Revista Iberoamericana, Vol. LXXVIII, Núm. 240, Julio-Septiembre 2012, 657-679

\title{
EL BLOG: ¿UNA NUEVA FRONTERA PARA EL ENSAYO?
}

\author{
POR \\ Stefano Tedeschi \\ “La Sapienza”, Università di Roma
}

El título de esta reflexión enlaza en una sola pregunta dos modos de escritura que, según la información de que dispongo y según la bibliografía consultada, se ha encontrado solo una vez, y a nivel periodistico: ${ }^{1}$ el del ensayo, en su significado más amplio, y el del $b l o g$, este nuevo espacio virtual que en los últimos años se ha ido extendiendo de forma casi epidémica en todo el mundo. La relación entre ambos se puede establecer en el nivel de la comunicación, y nuestro título podría leerse también: ¿ puede ser el blog una nueva forma de comunicación para los ensayistas? Y en caso de respuesta positiva, ¿qué pasa con la escritura de lo que estamos acostumbrados a leer y a llamar ensayo? Los ejemplos que nos ofrece la Red son ahora lo suficientemente heterogéneos y cuantiosos como para proponer algunas consideraciones sobre el tema, con la advertencia de que toda especulación sobre el mundo de la Red debe tener en cuenta la velocidad de los cambios que se viven en este espacio, a raíz de las nuevas formas de comunicación interpersonal propuestas en los últimos tiempos.

El itinerario que proponemos inicia con una breve reseña de los términos de la cuestión, empezando por las formas actuales del ensayo y las dificultades vividas por los sistemas de comunicación del saber, continuando con las propuestas que abre la Red, para después analizar el fenómeno del blog como espacio de reflexión intelectual, con algunos ejemplos entre los muchos ahora disponibles, y terminar con algunas observaciones sobre las expectativas y las incógnitas de la escritura ensayística en la Red, con todos sus retos, problemas y perspectivas.

EL ENSAYO EN LA RED

Hoy en día es posible encontrar en el ciberespacio cualquier tipo de escritura: también el ensayo está presente en todas sus formas, desde el texto filológico y académico hasta la intervención más comprometida o desenfadada. Lo que aquí nos interesa es la

1 Fernando García y Andrés Haz (1998). 
forma de ensayo, camaleónica y subversiva, experimentada en los últimos dos siglos en América Latina, ya analizada con resultados excelentes. ${ }^{2}$ José Miguel Oviedo menciona en su Breve Historia algunas de sus propiedades esenciales: un género determinado a ocuparse de todo, entrometido y preguntón, una escritura impertinente e insatisfecha de los discursos establecidos, y por esto siempre dubitativa, perpleja, en forma de ensayo, de prueba, de experimento, como recuerda su etimología francesa (11-14). Los autores más destacados del género dejan en sus páginas al mismo tiempo una imagen viva del yo como persona, de sus búsquedas, y de la sociedad donde vive: un yo autorial que va abriendo ventanas hacia el futuro, se pone inagotablemente en juego, y expresa un fuerte deseo de diálogo con el lector, tanto que a veces la forma se vuelve fragmentaria, casi imaginando una respuesta en los espacios blancos que deja la composición tipográfica. No habrá que olvidar finalmente la vocación disidente del ensayo, no sólo en sus representantes más comprometidos políticamente, sino también en los que cuestionan las formas usuales de elaboración artística y de comunicación.

En los últimos años quien ha experimentado la escritura ensayística ha tenido que reconocer una profunda crisis de las formas tradicionales de difusión de las ideas, una crisis que está haciendo tambalear periódicos, revistas culturales y publicaciones académicas, restringiendo los espacios para el debate de las ideas e incluso para la normal transmisión del saber. No hay duda de que las revistas culturales, que desde hace mucho tiempo habían sido la palestra para la irradiación de las nuevas tendencias, con las consecuentes controversias, están atravesando una crisis económica y de difusión de gran envergadura. No va mucho mejor para las revistas académicas, que corren el riesgo de volverse autorreferenciales, reduciéndose su público al limitado número de autores invitados y subscriptores institucionales. En este escenario, la Red se propone, quizás desde sus inicios, como un espacio abierto a un público universal, infinitamente mayor del que se podía imaginar antes, y las sucesivas innovaciones tecnológicas no han hecho sino aumentar las posibilidades de conexión y de navegación.

La Red, desde sus inicios, prometía romper el círculo cerrado de los lectores con su amplitud teóricamente infinita y la posibilidad dialógica que llevaba en su ADN. Ya su inventor, T. Berners-Lee, lo había dicho con claridad extrema:

El principio fundamental de la Red es que, una vez que se haya puesto a disposición un documento, una base de datos, una imagen, un sonido, un video, o una conversación interactiva, éste tendría que ser accesible para todos, con cualquier tipo de ordenador, en cualquier país [...] Convencer a la gente de introducir datos en la Red era a menudo sólo cuestión de hacerle cambiar su punto de vista, de hacerle pensar en el acceso de

2 Respecto a la inmensa bibliografía sobre el tema, una indicación básica no puede evitar los nombres de Martin G. Stabb (1967; 1994), de Earle y Mead (1973), de José Miguel Oviedo (1990), además de muchas compilaciones y antologías.

\footnotetext{
Sevista Iberoamericana, Vol. LXXVIII, Núm. 240, Julio-Septiembre 2012, 657-679 ISSN 0034-9631 (Impreso) ISSN 2154-4794 (Electrónico)
} 
un usuario no como interacción con, por ejemplo, un sistema de bibliotecas on-line, sino como navegación por una serie de páginas virtuales al interior de un espacio abstracto. Siendo capaz de hacer referencia a todo con la misma facilidad, la Red podría representar también las asociaciones entre cosas que podrían parecer ajenas entre sí, y que sin embargo comparten una cierta relación. (40-41, mi traducción)

Los ensayistas no han dejado pasar esta ocasión y ahora hacen circular el ensayo en la Red por lo menos en cuatro niveles. El primer nivel está constituido por las revistas académicas que tienen su edición online: los artículos que podemos leer en la versión impresa se cargan en la Red, sin modificaciones, y desde allí pueden ser consultados por lectores dispersos en toda la geografía del planeta, sea en forma gratuita como a través de servidores profesionales; obviamente la escritura en esta situación no sufre ningún cambio, ya que el texto es absolutamente el mismo en las dos versiones.

El segundo nivel se encuentra en las revistas académicas que tienen sólo su versión online: abandonando el papel, se dirigen al público del ciberespacio con el mismo rigor de las revistas tradicionales, pero a veces la escritura se va volviendo más legible, y la misma organización del texto se renueva: párrafos más breves, separados por espacios, una imagen gráfica más adecuada al nuevo medio y la idea de un posible público de lectores no especializados influye en los autores que escriben para este tipo de revistas. ${ }^{3}$

El destino final de todos estos textos se encuentra sin embargo casi siempre en las impresoras: cuando se encuentran aportes interesantes para la investigación, se guardan para una impresión sucesiva; se elige esta solución no sólo por razones prácticas, ${ }^{4}$ sino porque estudios han revelado que la lectura en la pantalla es un $25 \%$ más lenta, ${ }^{5}$ lo que puede explicar la sensación de cansancio que probamos al leer por mucho tiempo un texto en el ordenador.

El tercer nivel está integrado por las revistas culturales que existen sólo en la Red, y en este campo el mundo latinoamericano propone ejemplos muy notables: bastará recordar los docientos números de Letralia, la elegancia gráfica de Etiqueta Negra, o la riqueza de contribuciones de Crítica.cl, para señalar la relevancia que han ido adquiriendo en los últimos años, certificada en los dos encuentros de Revistas Digitales, celebrados en 2008 en Madrid y en el 2011 en Ciudad de México. ${ }^{6}$ Todas estas revistas

3 Se pueden consultar, como ejemplos muy diferentes, la revista Artifara, de la Universidad de Turín, Italia, y el proyecto recién estrenado de la revista Letral (se dan las indicaciones del sitio en la bibliografía).

4 En los últimos años, para salvar esta dificultad, se ha ido desarrollando la tecnología del e-book, que abre nuevas perspectivas para el almacenamiento de textos y la lectura, gracias a nuevas tecnologías de pantalla (los tablets) pero este tema excede las reflexiones de este artículo.

5 Nielsen explica este hecho en el capítulo 3 de su libro Designing Web Usability, especialmente en los apartados relativos a la escritura para la Red.

6 Todas las informaciones sobre el Congreso se encuentran al enlace: <http://www.miradamalva.com/ revistasdigitales/index.html>.

Revista Iberoamericana, Vol. LXXVIII, Núm. 240, Julio-Septiembre 2012, 657-679
ISSN 0034-9631 (Impreso) 2154-4794 (Electrónico) 
tienen diferentes secciones temáticas, y al lado de la crónica cultural, campo en el que desempeñan una función ya imprescindible, abren espacios para la escritura creativa y el ensayo, que pueden ser de muy diversa índole, pero reproduciendo casi siempre el modelo académico: aquí también se nota una tendencia a ser más breves, sin que esto signifique que haya normas establecidas sobre el número de páginas. ${ }^{7}$ La exigencia de la brevedad nace de la relación entre la arquitectura de la página Web y su legibilidad en la pantalla, un problema que se plantea desde los comienzos del diseño de la Red.

El cuarto y por el momento último nivel lo constituye la reciente experiencia de la escritura del blog. Esta nueva forma de comunicación presenta algunas importantes novedades y respecto al ensayo tradicional abre una posibilidad hasta ahora inédita, que es la interactividad con los lectores, un sueño que un escritor como Julio Cortázar había perfilado ya en los años sesenta. ${ }^{8}$

\section{EL BLOG Y SUS EJEMPLOS HISPANOAMERICANOS}

Desde que en 1997 se ha empezado a describir el fenómeno del blog muchas han sido las definiciones, ya sea desde un punto de vista técnico como desde una reflexión más cualitativa: así se han ido perfilando diferentes escuelas respecto a los posibles escenarios de su desarrollo.

Desde un punto de vista esencialmente técnico el blog es, como dice Bruguera:

[...] una página web, en la que el sistema de edición y publicación se ha simplificado hasta el punto que el usuario no necesita conocimientos específicos del medio electrónico ni del formato digital para poder aportar contenidos de forma inmediata, ágil y permanente, desde cualquier punto de conexión a internet. (13)

Las características que el mismo Bruguera y otros ${ }^{9}$ señalan para definir un blog desde un punto de vista semántico permiten aislar algunos temas: el blog se presenta entonces como un espacio de comunicación, de intercambio de informaciones, historias personales, opiniones, abierto a todos de manera que cualquier usuario de la Red puede abrir un blog personal, y que todos pueden intervenir en esta comunicación, participando en lo que los expertos llaman The Big Conversation.

7 En Letralia, la norma es: "En narrativa, ensayo y otros géneros, envíenos un mínimo de una cuartilla. No imponemos límites en cuanto a una extensión máxima”.

8 Sobre las relaciones posibles entre Cortázar y la Red se empiezan a escribir ensayos muy interesantes, como por ejempo el de Rob Rix (2008). Se podrían considerar, en cierta medida, sus libros “misceláneos” (Último Round y La vuelta al día en ochenta mundos, de Cortázar) como antecedentes de los blogs literarios y ensayísticos.

9 La bibliografía sobre el blog ya es importante: recordamos aquí los textos de Di Fraia (2007), Granieri (2005), Dellarocas (2003).

Revista Iberoamericana, Vol. LXXVIII, Núm. 240, Julio-Septiembre 2012, 657-679
ISSN 0034-9631 (Impreso) 
El nombre mismo de este espacio de comunicación nos ayuda a perfilar otra peculiaridad del blog, como Bruguera nos recuerda:

En su origen, weblog juntaba la referencia al formato web de publicación electrónica con el verbo ingles to log -anotar- y la expresión náutica log on ship -cuaderno de bitácora o diario de abordo. Una asociación de las acciones de registro y navegación que en inglés pronto evolucionó hacia la expresión abreviada de blog, y que en español derivó hacia bitácora y cuaderno de bitácora. (15)

Dejando por el momento de lado las posibles relaciones que en el mundo hispanoamericano se abren frente a palabras como "diario de abordo" o "bitácora", habrá que añadir a esta definición etimológica que todo blog es un "diario intelectual”, incluso en la forma del blog más personal, ya que la huella que un individuo deja en la Red, en el momento en que elige compartirla con otros ya la eleva a una dimensión más compleja que el simple registro de eventos.

En este sentido habrá que revisar las tentativas de clasificación de los blogs que se han propuesto en los últimos años, ${ }^{10}$ ya que ninguna podrá contener un juicio de valor, sino simplemente registrar diferencias respecto al contenido, en relación a un autor individual o a autores colectivos, o a formas de escritura que pueden variar desde la más personal hasta las más especializadas, y finalmente respecto a los materiales contenidos en el blog (imágenes, vídeos, etc.).

El blog nace así como un "ambiente psico-tecnológico con alto valor identitario" (Di Fraia 36) en el cual se experimenta una escritura del yo que se abre a la intervención directa de los otros por medio de la inserción de comentarios (llamados post) puestos en orden cronológico inverso (aunque esta característica, puesta por default, puede ser modificada).

La novedad del blog respecto a otras formas de ensayo en la Red se encuentra así justamente en sus orígenes: mientras las otras revistas digitales proponen una versión online del ensayo tradicional donde los cambios en la escritura son mínimos, el blog nace como un instrumento digital, propio del ciberespacio, y si algunos lo han relacionado con los antiguos diarios personales, escritos en libretas de toda forma y tamaño, no hay duda que presenta características propias de absoluta novedad a tener en cuenta en el momento de analizar su presencia en la Red.

Antes del trabajo de análisis hay que señalar la diferencia entre dos tipos de blogs: si por un lado existe el blog individual, creado por una persona real que propone en la Red su historia, sus ideas, sus preferencias y sus creaciones, y la mayoría de la blogósfera está constituida por este tipo de blogs, por otro lado se encuentran los que

${ }^{10}$ Una presentación de las diferentes taxonomías de los blogs se encuentra en Di Fraia (2007) y en Hevern e Pugliese (2005).

ISSN 0034-9631 (Impreso) 
se pueden definir como periodísticos, en conexión a ediciones digitales de importantes periódicos o revistas, blogs encargados a firmas importantes, y que no aparecen en la versión impresa. La escritura ensayística se puede encontrar en ambos tipos, pero esta diferencia va a tener importantes consecuencias sobre la estructura del blog y su forma de elaboración.

En el campo de los blogs personales se han ido desarrollando en los últimos años los que se llaman blogs literarios, publicados por escritores y críticos literarios, que a través de este medio dan a conocer su producción más reciente, sus ideas sobre la creación, sus reflexiones sobre colegas y libros, tanto del presente como del pasado. Muchos escritores españoles e hispanoamericanos ya tienen este espacio personal, y por ejemplo es posible acceder a algunos de ellos a través de un portal común, $E l$ Boomeran (g), que reúne, entre otros, los enlaces a los blogs de Alberto Fuguet, Edmundo Paz Soldán, Iván Thays y Sergio Ramírez. ${ }^{11}$ Uno de los blogs más sugerentes de este grupo, el Moleskine literario del peruano Iván Thays, nos conduce al que parece ser el más interesante para nuestro tema (Edmundo Paz Soldán, 2007): en 2006 Moleskine Literario ha realizado una encuesta para escoger el más influyente crítico literario del Perú, y el elegido ha sido Gustavo Faverón Patriau, no sólo por sus ensayos y artículos académicos, sino por su blog Puente aéreo, punto de referencia desde 2005 para cualquier lector, profesional o no, de literatura hispanoamericana, y en especial peruana. Desde entonces su importancia ha ido aumentando, fomentando también la creación de blogs de otros autores, en competencia, cuando no en abierta polémica, con el de Faverón.

Puente aéreo no deja espacio a la creación literaria, y es un magnífico ejemplo de lo que estamos investigando, como se puede leer en su página de inauguración:

[Puente aéreo] no quiere ser otra cosa que un espacio abierto para el intercambio crítico. Quedan bienvenidos quienes quieran usar este sitio para hacer públicas sus opiniones en relación con temas de cultura y literatura en un sentido amplio. Se admite aquí la discusión y también, por qué no, la polémica.

El blog se ha abierto en octubre de 2005, y, al 31 de diciembre de 2010 tenía 1.600 entradas, con puntas mensuales de setentisiete: esto significa una puesta al día constante, trabajo no tan frecuente en el mundo de la Red, ${ }^{12}$ y sobre todo una notable variación en los temas y en las cuestiones abordadas.

${ }^{11}$ Véase $<$ http://www.elboomeran.com/>.

12 En los diez años de vida de esta forma de comunicación se han abierto en el mundo algunos millones de blogs, pero la vida media de muchos de ellos ha sido muy breve, así como la actualización "frecuente y regular” no es una característica constante. El blog puede ser de esta manera un espacio provisional, quizás ya sustituido por otras formas de intercambio de historias y de informaciones, como Facebook o Twitter, que en efecto parecen haber sustituido el blog como diario personal, sobre todo para las generaciones más jóvenes.

Revista Iberoamericana, Vol. LXXVIII, Núm. 240, Julio-Septiembre 2012, 657-679
ISSN 2154-4794 (Electrónico) 
La estructura gráfica de Puente aéreo no tiene de por sí características especialmente llamativas: un dirigible vuela con el título sobre la página principal, con las entradas a la izquierda y a la derecha los enlaces a otras páginas, y el archivo completo del blog; los comentarios de los lectores se encuentran en otra página, alcanzable con un click sobre la palabra comentarios, como es usual en otros blogs. La página de las entradas es mensual, es decir que se puede acceder a todas las del mes moviendo el ratón, y al final de la página es posible pasar al mes precedente. Llama la atención el cuidado en la selección de las imágenes: cada entrada tiene una (o más de una) imagen de referencia de muy buena calidad gráfica, y hay también enlaces en la columna de derecha hacia obras de artistas visuales; el resultado parece agradable, sin ser demasiado vistoso ni de difícil lectura: el texto queda en el centro de la atención, escrito además en letras bastante claras, pero no ocupa toda la pantalla, como ocurre en otros casos. El modelo gráfico del blog no es especialmente innovador, pero parece construido con atención a los detalles, y resulta funcional al uso de su autor.

Los comentarios de los lectores están controlados por el moderador del blog, el autor mismo, para evitar intrusiones ofensivas, inadecuadas, o simplemente repeticiones, y cada entrada tiene un número variable de comentarios. Esta práctica de control está muy difundida en la Red, y tiene consecuencias de un cierto relieve en la construcción del diálogo con los lectores.

Otro aspecto interesante del blog de Gustavo Faverón es su política de enlaces; hemos dicho que en la columna de la derecha están presentes tres series de enlaces: los asiduos, mira esto (páginas culturales de varios tipos), otros blogs, con un total (claramente variable) de alrededor de cuarenta enlaces. Pero la estrategia de Puente aéreo no termina aquí: casi en todas las entradas hay enlaces con otros artículos, páginas de referencia, u otros blogs, relativos al tema tratado, señalados con un color diferente de letra y un subrayado de la palabra. Este sistema configura una red de referencias que pone al blog de Faverón en el centro de una telaraña de enlaces que le permite entrar en un intercambio muy importante para la presencia del blog en la Red. ${ }^{13}$

Lo que resulta más interesante para nuestro estudio es la variedad de los contenidos del blog: analizándolos con atención se puede apreciar que una parte se ocupa de la actualidad literaria y política, sobre todo del Perú, y en este sentido el blog de Faverón puede ser asimilado a lo que Paz Soldán define como heredero de la crónica ("A Ciberliterary Afterword” 260). Otra parte del blog aparece sin embargo desligada de las circunstancias de lo cotidiano, y allí se puede encontrar reflexiones sobre libros y literatura (no solamente hispanoamericanos), cine, música, comics, artes visuales, con

${ }^{13}$ Se habla de una verdadera "economía política” de los enlaces, que influye sobre la presencia de un blog en Google (Granieri 40).

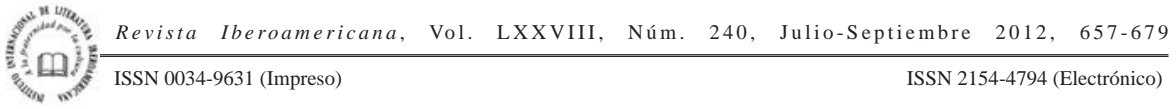


una atención especial a los cruces que se dan entre las diferentes formas artísticas. La mayoría de las entradas de este tipo no son demasiado largas, y entran claramente en la categoría del ensayo, como podemos observar en tres ejemplos significativos.

El primero, del 27 de julio 2006, se títula Crack y McOndo vs...¿ quién? y empieza con una rápida presentación del estado de la cuestión, con referencia a la polémica desatada por la irrupción de estos dos grupos de jóvenes escritores en el panorama de la literatura hispanoamericana:

Hace años se viene escuchando lo mismo con variantes distintas: Alberto Fuguet ha dicho mil veces que su grupo virtual, McOndo, surgió como respuesta a la pesada tradición latinoamericana de lo real maravilloso, que asfixiaba y entorpecía las posibilidades de nuestra literatura de representar a una América Latina distinta, a años luz, como suele decir Alberto, de las vírgenes voladoras y los ancianos alados de García Márquez.

También Jorge Volpi y los muchachos del crack mexicano han señalado algo similar más de una vez, y Jorge lo repite ahora en una entrevista hecha en Lima y publicada por Peru.

Se resumen después las propuestas de los dos “grupos” de nuevos escritores frente al realismo mágico y se empieza a divisar la observación crítica de Faverón respecto al panorama literario en que se insertan el Crack y McOndo:

Cuando Volpi y Fuguet, el Crack y McOndo, aparecieron en la escena literaria, es justo decir que los escritores que dominaban el paisaje eran en su mayoría absoluta y radicalmente ajenos al realismo mágico y lo real maravilloso. A principios de los noventa, sobrevivía la enorme lectoría de García Márquez, pero estaba él mismo ya bastante distanciado del realismo mágico. [...]

El blog concluye, pocas líneas más abajo, con la consideración final y la pregunta que abre la discusión:

Habían despertado y llegado a la fama, eso sí, los hijos ilegítimos de García Márquez, como Isabel Allende, en libros que la crítica demolió rápidamente, aunque el público los favoreciera con largueza; libros que transformaron el realismo mágico en receta de best sellers, ya desescamado y deshuesado. Pero al hacer eso, en verdad le estaban tirando una lápida, acaso prematura, a ese modo literario.

Ahora bien: ¿contra Isabel Allende es que se levantaban McOndo y el Crack? Difícil creerlo. $^{14}$

\footnotetext{
${ }^{14}$ Véase comentario en: <http://puenteareo1.blogspot.com/2006_07_01_archive.html>.
}

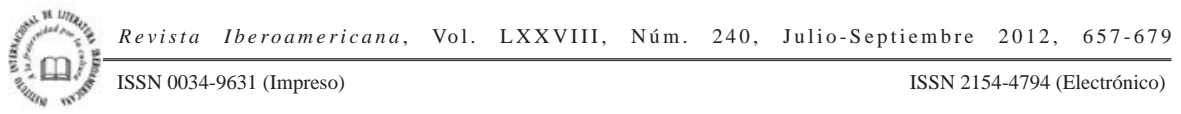


En este caso los comentarios amplían la reflexión sobre el tema y el mismo Faverón añade una interesante consideración sobre McOndo y el Crack como discursos armados “[...] para ‘el mundo’ y no para sus propios connacionales ni para América Latina en general, lo cual no sería problemático si no fuera por el hecho de que ellos sólo son oídos en sus países y en América Latina”. ${ }^{15}$

Otro ejemplo se puede encontrar en la entrada del 21 de julio 2007, sobre los best sellers y su acogida crítica (Como de quien viene. ¿Debe la crítica literaria evaluar con el mismo rasero todos los libros?). Aquí la reflexión nace de las diferentes opiniones sobre el sitio web Metacritic, "que recolecta en una base de datos las reseñas de la prensa de lengua inglesa sobre libros, discos y películas.” Después de una "catarata de cifras" sobre las evaluaciones más recientes, Faverón llega a lo que más le interesa: resulta que en Metacritic la última entrega de la saga de Harry Potter tiene una puntuación más alta que muchos escritores “consagrados”, y esto abre una serie de consideraciones sobre la función de la crítica, sobre todo periodística, para concluir con una serie de preguntas puestas aquí también adrede para abrir la discusión:

Es curiosa esa actitud, porque, a fuerza de querer lucir abierta, desenfadada, inclusiva, muy muy postmo, no hace sino subrayar el hecho de que estos críticos perciben claramente la distancia entre dos distintas esferas literarias: por un lado, una literatura comercial, que potencia el atractivo inmediato de las narraciones populares y desescama otras tradiciones para generar libros de consumo inmediato; por otro lado, una literatura riesgosa, de descubrimiento y experimentación, de búsqueda estética e intelectual, dispuesta a muchas cosas, incluso al fracaso.

¿Es justo que la crítica relativice tanto sus juicios? ¿Es justo que se acabe por aceptar consensualmente que los libros de Harry Potter son -de alguna manera caprichosa, casi incomprensible- superiores a The Plot Against America o Kafka on the Shore? $¿$ ¿Soy demasiado conservador si apunto que decir eso es un poquito como decir que el campeón de la Segunda División es mejor que el subcampeón del Mundial? ¿Existen o no existen segundas divisiones en la literatura ${ }^{16}$

Esta entrada provoca numerosos comentarios (treinta en ocho días) que configuran una reflexión “a varias voces” sobre el tema, con algunas opiniones de valor, aunque no aportan ideas verdaderamente novedosas sobre un tema ya abordado en una bibliografía imponente. ${ }^{17}$

$15<$ https://www.blogger.com/comment.g?blogID=17920328\&postID=115404434796111891>.

$16<$ http://puenteareo1.blogspot.com/2007_07_01_archive.html>.

17 Un buen número de entradas están dedicadas, como se podía suponer, a Roberto Bolaño, el escritor chileno sobre el cual Faverón ha publicado un libro importante, Bolaño salvaje, con Edmundo Paz Soldán (2008). Juntando todos los apuntes dejados en el blog se podría construir un nuevo libro sobre la escritura de Bolaño, casi una colección de microensayos.

ISSN 0034-9631 (Impreso) 
Lejos de formar un conjunto caótico y disgregado, y de ser un simple alarde de sabiduría, esta variedad se mueve alrededor de la voluntad de construir una reflexión unitaria: a veces las entradas nacen de una demanda de los lectores, o de otros bloggers, o de una provocación de la actualidad, pero siempre llevan a otro nivel de especulación, a una calidad del blog que Faverón considera tenga que ser muy alta, como afirma comentando un artículo de Jonathan Franzen:

\begin{abstract}
Porque detrás de lo que a Franzen le preocupa no está el tema de la tradición versus la modernidad, o el de la institucionalidad ante la liberación democratizadora de internet. No. Lo que hay tras sus palabras es un reclamo en favor de la especialización y en contra de la aceptación de la mediocridad crítica como norma: reclama ante el temor de que la imposición de la medianía como standard, a través de la institucionalización de los blogs como espacios que reemplacen a la crítica de prensa, acabe por aniquilar para siempre la posibilidad más fecunda de la relación escritores-críticos-lectores. [...] No le falta razón, si uno lo ve de esa manera. La blogósfera y, en general, la simplificación del acceso a internet, con sus innumerables beneficios y su apertura democratizante, trae también males, y uno está en la disolución de los criterios de juicio especializado en la literatura y las artes en general (acaso en las humanidades todas, y posiblemente más allá). En comparación con los medios tradicionales, Internet es más fácil de acceder para todos, tanto quienes quieren publicar en ella como quienes quieren leer lo que en ella aparece. Si abrir un blog toma 30 segundos, ese es exactamente el tiempo que le toma a alguien convertirse, en la práctica, en un blogger literario. Convertirse en crítico -no sé si lo recuerdan- solía demandar un esfuerzo mayor. ${ }^{18}$
\end{abstract}

Si Puente aéreo es un ejemplo del blog personal que contiene una escritura de tipo ensayístico, del lado de los blogs periodísticos hay que señalar los cuatro abiertos por Letras Libres en su página Web: a partir de mayo de 2007 la revista mexicana ha invitado varios escritores a tener un blog individual: en agosto 2011 se cuentan 7 blogs individuales, más 5 “invitados” y 5 de la Redacció. Los primeros fueron José de la Colina (Correo fantasma, mayo 2007) y Guillermo Sheridan (El Minutario, mayo 2007), continuando con Roger Bartra (La jaula abierta, agosto 2007) y Christopher Domínguez Michael (Fragmentos, agosto 2007), cuatro autores que han publicado importantes volúmenes de ensayos en diferentes ámbitos.

Las características de los blogs de Letras Libres evidencian algunas diferencias pequeñas pero sustanciales entre el blog personal y los institucionales. Si una primera mirada no revela grandes cambios, un análisis más puntual muestra en el espacio de la revista algunas ausencias. El texto queda del mismo modo a la izquierda de la pantalla, hay aquí también una gran atención a las imágenes, pero faltan totalmente los enlaces

${ }_{18}$ Véase “50 mil gritones incompententes”: <http://puenteareo1.blogspot.com/2008_01_01_archive.html>.

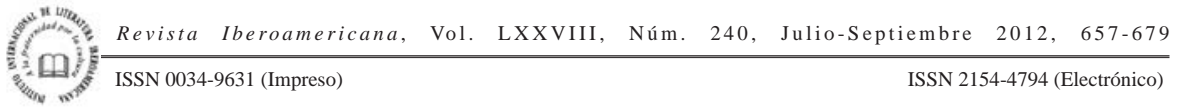


a otros blogs, así como son mucho menos evidentes los enlaces al interior de los textos propuestos, y la estadística de las entradas confirma que la puesta al día es mucho menos constante que en Puente Aéreo. A la fecha de diciembre 2010 los blogs de Guillermo Sheridan y de José de la Colina tenían respectivamente 381 y 339 entradas, mientras el de Domínguez Michael tenía 85 y el de Roger Bartra 46: resulta claro que en estos casos la actividad del blog no necesita de una presencia cotidiana para asegurar su visibilidad, ni de entrar en aquel mercado de los enlaces que hemos señalado antes para encontrar un hueco en la jungla de la Red. El prestigio de la revista y de los autores convocados ya asegura una cuota fija de lectores, y esto se nota también en los comentarios, que provienen muchas veces de verdaderos adictos a los diversos autores.

Los cuatro blogs, iguales en su estructura visual, se diferencian por los temas abordados y obviamente por el corte de cada autor: el de José de la Colina, Correo fantasma, acoge también minicuentos y poemas del autor, así como muchas entradas sobre diferentes aspectos de la vida cotidiana en el Distrito Federal, sea como memoria de costumbres desaparecidas o como denuncia de desastres urbanísticos. José de la Colina quiere establecer abiertamente un diálogo con los lectores, tiene un público importante. De la Colina es el único entre los cuatro que responde con frecuencia a los comentarios siempre empezando con una frase de cortesía muy acertada (gracias por leerme); las entradas y los comentarios llegan a formar a veces un conjunto de reflexiones de gran interés que ocupan incluso un tiempo bastante largo. El autor es también el único que interviene en la polémica sobre una presunta censura del administrador del blog, proponiendo dejar libertad absoluta a los comentarios de los lectores, una propuesta que resulta inaplicable ya que esto significaría dejar campo libre a comentarios descabellados y sin importancia que sofocarían los verdaderamente interesantes.

Esta polémica nos revela un aspecto del blog que ya se había asomado en Puente aéreo, es decir, su naturaleza dialógica: en realidad el diálogo con los lectores viene filtrado y muchas veces se limita a breves intervenciones de apreciación o a correcciones de pequeñas faltas, y muy raras veces llega a provocar nuevas entradas del autor, sea en los blogs personales como en los institucionales. El diálogo posible resulta entonces como una promesa, un horizonte todavía por alcanzar, con consecuencias que se verán mejor en las reflexiones conclusivas.

El Minutario de Guillermo Sheridan, como recita el subtítulo del blog, es un "cuaderno en que el escribano o el notario ponía los borradores o minutas de las escrituras o instrumentos públicos que se otorgaban ante él” y resulta el más debatido de los cuatro, como se podía suponer, considerado el compromiso intelectual del autor. Un gran espacio se da a la actualidad política y a los debates culturales, y tiene una gran audiencia: los comentarios llegan a números importantes y la polémica se enciende entre los mismos comentaristas. En el caso de Sheridan, de todos modos, el estilo del blog se parece más bien a los blogs de la versión online de muchos periódicos del mundo, y

\footnotetext{
Revista Iberoamericana, Vol. LXXVIII, Núm. 240, Julio-Septiembre 2012, 657-679 ISSN 0034-9631 (Impreso)

ISSN 2154-4794 (Electrónico)
} 
las noticias del día no llegan a provocar un espacio de reflexión más amplio. El aporte del autor resulta siempre crucial, pero no podemos hablar de ensayos, sino más bien de micro-panfletos, casi de pequeños manifiestos.

El título de La jaula abierta viene de un famoso ensayo de Roger Bartra, y el blog es, al contrario del de Sheridan, el que más quiere alejarse de la cotidianidad, con el intento de abrir una reflexión sobre aspectos puntuales de la sociedad mexicana con un sector de lectores que demuestra apreciar este proyecto: los comentarios no son excesivos, ${ }^{19}$ pero muchas veces son de buena calidad y revelan una cierta afinidad con los temas tratados. Las entradas son en general bastante largas y no se alejan mucho del estilo del autor.

El de Domínguez Michael es el que nos interesa más en nuestra investigación, ya que muestra, desde el título, Fragmentos, la voluntad programática de moverse en el campo del pensamiento breve, de la anotación urgente. Además la calidad de los libros publicados por el autor asegura un alto nivel de escritura y una cuidadosa selección de los temas. El análisis del contenido del blog confirma esta hipótesis: las entradas del blog se refieren de manera casi exclusiva a la literatura, muchas veces como reseñas de libros, a veces como largos ensayos, divididos en capítulos, como él sobre el filólogo danés Georg Brandes, y sólo algunos se acercan a temas más generales. Cuando esto ocurre se puede apreciar toda la calidad de la reflexión de Domínguez Michael: la escritura del crítico mexicano no pierde su fuerza al pasar al nuevo medio, los lectores se sienten llamados a intervenir y los comentarios resultan acertados. Se puede notar que el diálogo con los lectores no es muy frecuente y los comentarios no son numerosos. Se puede afirmar que en el caso de Domínguez Michael la escritura ensayística se asoma a la pantalla pero no termina de acoplarse perfectamente con ella. ${ }^{20}$

Un tercer ejemplo que podemos presentar en nuestra búsqueda en la Red es el de un blog especializado, La Peña Lingüística, de Miguel Rodríguez Mondoñedo, un lingüista que trabaja en la Universidad de Connecticut. La presentación del blog es muy parecida a los otros, y la puesta al día muy irregular ${ }^{21}$ e incluso la motivación que el autor nos presenta parece casi una "autoreducción":

${ }_{19}$ No resulta casual entonces que los comentarios más numerosos, incluso algunos muy “violentos”, se registran respecto al blog del 12 de febrero de 2008, sobre La virgen de Chingadalupe, que causó un verdadero revuelo entre los lectores.

${ }^{20}$ Las diferencias existentes entre estos dos tipos de blogs remiten tal vez también a una diferencia generacional, ya que los ensayistas de Letras Libres llegan al nuevo medio después de una larga trayectoria en la edición impresa, mientras muchos de los otros van utilizando los nuevos medios a la vez que van publicando ensayos en revistas y libros. En este sentido parece muy interesante la reciente introducción en Letras libres de las Bitácoras Invitadas, cinco blogs de jóvenes escritores y de una fotografa.

${ }^{21}$ En los últimos años entre un post y otro pueden pasar incluso diez meses.

Revista Iberoamericana, Vol. LXXVIII, Núm. 240, Julio-Septiembre 2012, 657-679
ISSN 0034-9631 (Impreso) 
Por varios años, muchas personas -amigos, colegas y alumnos- me han enviado preguntas y comentarios sobre los “errores lingüísticos” que se cometen en la prensa todos los días. Casi siempre, las observaciones vienen con muy alarmantes advertencias sobre la ruina del idioma y el descalabro de la inteligencia. Aunque yo no comparto la alarma de estos amigos respecto de la conexión entre el nivel de inteligencia y el uso del lenguaje [... ] algunas de esas innovaciones, hay que confesarlo, son muy divertidas. Así que me he propuesto coleccionarlas y, cuando pueda, comentarlas.[...]

Quiero dejar en claro que este no es un blog para burlarse de nadie, ni para recomendarle a nadie cómo hablar o cómo escribir. Tampoco es un lugar para lamentarse de nada. Por el contrario, es un lugar para celebrar la riqueza y la variedad del español (es la peña lingüística, no la pena linguistica, a pesar de que esto último es lo que diga el discriminador URL). ${ }^{22}$

En realidad el blog resulta ser mucho más que un simple catálogo de curiosidades lexicales o de barbaridades lingüísticas y se abre a reflexiones sobre el lenguaje, las teorías lingüísticas, la historia cultural. La entrada del 26 de agosto 2008, por ejemplo, vierte sobre la lingüística popular y discute el voseo argentino en respuesta a un blog del sociólogo Gonzalo Portocarrero. Lo que aquí interesa es la modalidad de construcción del texto que se configura como un buen ejemplo de ensayo en la Red: el tema se introduce haciendo referencia a Leonard Bloomfield, con una cita de un texto suyo y a través de dos enlaces; seguidamente se pasa al texto de Portocarrero (otro enlace) con las observaciones de Rodríguez Mondoñedo en referencia a lo que él describe como "mitos lingüísticos". Al final encontramos una label, ${ }^{23}$ instrumento que permite de reagrupar las entradas según los temas, y después los comentarios, que en este caso son diez y siete, que prolongan la reflexión hasta el 25 de septiembre. Toda la discusión se mueve alrededor del concepto de agramaticalidad, con ejemplos de varias modalidades del español hablado. ${ }^{24}$

El texto de Rodríguez Mondoñedo se propone entonces como una contribución rigurosa sin dejar de ser atractiva, como casi todas las de su blog, que además contienen vídeos, como por ejemplo los de las publicidades en quechua y aymara de una compañía de telefonía móvil en la entrada "De profundo a contemporáneo: el quechua nuestro". ${ }^{25}$

$22<$ http://lapenalinguistica.blogspot.com/2006_05_01_archive.html>.

${ }^{23}$ La label, llamada también tag, es un instrumento que permite reagrupar las entradas según temas, que resulta muy útil en el momento de leer blogs con muchas entradas, pero no todos los autores utilizan este instrumento.

$24<$ http://lapenalinguistica.blogspot.com/2006_05_01_archive.html $>$.

$25<$ <ttp://lapenalinguistica.blogspot.com/2006_05_01_archive.html> (siendo aquí también un blog con páginas mensuales, la referencia bibliográfica es la misma que la anterior).

ISSN 0034-9631 (Impreso) 
VOLVIENDO A LA PREGUNTA

Todos estos ejemplos nos conducen otra vez a la pregunta inicial: ¿en qué medida el espacio del blog puede ser considerado una nueva frontera del ensayo? Algunas características que se han ido evidenciando permiten apreciar ciertas propiedades en común, y dejan vislumbrar que la escritura del blog abre nuevas perspectivas sobre la forma del ensayo, sobre todo si evitamos la consabida trampa de Kant con el ornitorrinco, ${ }^{26}$ que se puede repetir cada vez que aparece en el mundo algo incomparable con nuestros conocimientos.

La primera peculiaridad que se puede subrayar nace de la forma que presentan los blogs analizados, una forma que crea una condición de pluralidad, por la variedad de los temas abordados y gracias al movimiento de los enlaces internos: cada uno de ellos puede abrir una ventana hacia una nueva y posible aventura del conocimiento. Se proponen, por lo tanto, como textos que nacen y viven dentro de una red, de una biblioteca que puede ser compartida con el lector. Si una de las características de los grandes ensayistas es justamente la de convocar en pocas páginas las más variadas referencias culturales, el blog contemporáneo permite entrar en contacto directo con estas referencias, creando un efecto de vértigo, arriesgado pero fascinante.

De hecho, el riesgo que se podría correr aquí es el de la dispersión, o, aún peor, el de quedarse en la superficie de las cosas y de las ideas, como Bouvard y Pecuchet, pero la aventura de la Red acepta este riesgo hasta transformarlo en el placer de ser un flâneur del espacio virtual sin pretender transformarse en una enciclopedia virtual. ${ }^{27}$

Este aspecto del blog contemporáneo recuerda muy de cerca la situación de las causeries rioplatenses de la generación del ochenta en Buenos Aires: allí también se habla, por ejemplo, de un "despilfarro" intelectual, de una dispersión de la inteligencia crítica en géneros menores como la conversación, los apuntes, las notas periodísticas, y al mismo tiempo de una oscilación "entre la preminencia de lo efímero (la conversación, la vida mundana) y la voluntad de preeminencia, un yo que a la vez se pone en primer plano y se escamotea” (Campra 99). Afirmaciones muy parecidas se podrían repetir, mencionando sólo el mundo hispánico, al referirse a las tertulias cubanas de mitad del siglo xix o las madrileñas del primer tercio del siglo xx, todas experiencias que

\footnotetext{
26 Me refiero aquí al ensayo de Umberto Eco (1997) sobre la famosa cuestión de las dudas de Kant frente a este animal tan nuevo para el siglo XVIII como el ornitorrinco.

${ }^{27}$ Italo Calvino (1998), hablando del escritor italiano Carlo Emilio Gadda, introduce el concepto de multiplicidad: "[en los escritos de Gadda] cada mínimo objeto está contemplado como el centro de una red de relaciones que el escritor no puede dejar de seguir, multiplicando los detalles de manera que sus descripciones y divagaciones se vuelvan infinitas. Cualquiera que sea el punto de partida, el discurso se ensancha para abarcar horizontes cada vez más vastos, y si pudiera seguir desarrollándose en todas direcciones llegaría a abarcar el universo entero” (110).
}

Revista Iberoamericana, Vol. LXXVIII, Núm. 240, Julio-Septiembre 2012, 657-679
ISSN 2154-4794 (Electrónico) 
renovaron de manera radical la vida intelectual y la producción literaria de aquellos años, dejando detrás de sí una inconfundible atmósfera de fugacidad, de palabras que se pierden para siempre.

En la Red las conversaciones en cambio dejan huellas visibles, son textos que hablan, aunque no podemos prever por cuánto tiempo dado el caracter a veces provisional del sistema de organización de la misma Red. Además, para establecer el diálogo los blogs utilizan formas de comunicación múltiples entre las cuales adquiere siempre mayor trascendencia el uso de las imágenes, que podría parecer obvio, considerado el medio de transmisión, y que alcanza una dimensión más problemática observando la función de los dibujos, las fotos, los vídeos respecto a los textos.

En los blogs analizados, y en casi todos los que he visitado hasta ahora, la imagen tiene siempre una presencia significativa y funciona a diferentes niveles de integración. Un primer nivel es simplemente denotativo, como en el caso de los blogs -reseñas donde la cubierta del volumen o la foto del autor acompañan la entrada-: ninguna información más pasa a través de la imagen. Otro nivel, que podríamos definir connotativo, es el de una función dialógica entre el texto y la imagen: la foto, o el dibujo, se sitúa en un plano no inmediatamente ligado a la parte escrita, sino que entra totalmente en la reflexión y no se puede leer sin mirar la imagen, así como ésta resultaría incomprensible sin el texto. Un nivel que se puede apreciar, por ejemplo, en la entrada de Puente aéreo del 20 de julio 2007, dedicada al escritor peruano Jaime Bayly, con el título Roman à clef: la carta tapada, y el subtítulo Jaime Bayly y el costumbrismo contempóraneo. La imagen nos muestra un dibujo de una elegante mujer del siglo xix, de espaldas, probablemente una de estas estampas limeñas tan de moda por entonces, ${ }^{28}$ mientras el texto critica la lectura equivocada que se hace de la narrativa de Bayly en relación con un cierto chismorreo literario muy de actualidad, y no sólo en el Perú. La imagen puede ser leída de diferentes maneras: como una referencia al costumbrismo, una censura respecto a un cierto secretismo del mundo literario (la mujer está de espaldas y no se le ve la cara) o una alusión a las modas literarias. Pero son justamente estas referencias múltiples las que permiten tantas lecturas posibles: se evocan al mismo tiempo la frivolidad, las relaciones mutables entre autor y público, el problema del éxito literario en una sociedad de masas, la complejidad de las relaciones entre producto artístico y sistema económico, y el texto y la imagen se entrecruzan indefinidamente.

Es posible también encontrar imágenes sorprendentes que chocan con el título del blog, creando un efecto de oxímoron que atrae el lector y lo introduce en la lectura: aquí

28 Por un breve periodo las entradas del blog de Faverón han llevado también las referencias de las fuentes de las imágenes, pero esta costumbre desaparece después del 20 de julio de 2007. Por un lado deja total libertad al lector para interpretar la imagen, por otro lado requiere a veces un exceso de competencias visuales.

\footnotetext{
Revista Iberoamericana, Vol. LXXVIII, Núm. 240, Julio-Septiembre 2012, 657-679 ISSN 0034-9631 (Impreso) 
se advierte otra peculiaridad del blog-ensayo, de este texto que sale de la página escrita del libro para proponerse a un público potencialmente universal. Abrir una página web no es lo mismo que abrir un volumen de ensayos: en la Red la competencia es mucho más fuerte y la tentación de pasar a otra página, a otro enlace, resulta infinitamente más atractiva. Para convencer al lector a quedarse, a leer nuestra página y no otra, la imagen puede así funcionar como en la publicidad, y el ensayo tiene que negociar su nivel de escritura con las estrategias de posicionamiento en la Red.

Aún más interesante es el caso de la inserción de vídeos en los blogs, como en el caso ya recordado de La peña lingüística: el posible diálogo textual llega a ser triangular, añadiéndose el lado audio a los otros dos. Resulta evidente que aquí la construcción del blog tiene que ser muy cuidadosa para evitar que uno de los elementos domine a los otros (en especial la parte vídeo, con su carga semántica tan fuerte), pero en los ejemplos observados existe una copresencia de texto, imagen y audio que construye una forma de escritura muy novedosa, que por cierto entra en la categoría del ensayo, y al mismo tiempo abre vías nuevas a la elaboración crítica.

El peligro que se puede señalar aquí es doble: por un lado la imagen puede reducirse a un simple adorno, una bonita ilustración sin profundidad, mientras por otro lado la escritura podría resultar sólo una acotación, la explicación de una imagen que resultaría impactante aun sin comentarios. Este tipo de riesgo nos permite observar que un blog necesita una enorme atención en su construcción material, quizás mayor que en el caso de la escritura tradicional, y que justamente esta atención a la calidad de todas las partes implicadas es uno de los factores que permite la sobrevivencia de un blog en un mundo, el virtual, donde la capacidad de durar en el tiempo es una de las cuestiones más problemáticas.

Esta atención a la construcción concreta de un blog nos lleva a la cuestión de la forma de la escritura. Es evidente que el formato reducido del blog solicita el uso de técnicas ya ampliamente desarrolladas a lo largo de la historia, pero habrá que preguntarse si la novedad del medio provoca cambios en estas técnicas y, eventualmente, en qué dirección.

Resulta claro que el blog quiere evitar el paso por la impresora y paliar el efecto negativo de la lectura en pantalla al que se hacía referencia antes. La vía que emprende es la de la brevedad, unida a una inevitable búsqueda de la palabra exacta, de la eliminación de cualquier elemento redundante: de hecho, si copiamos los textos del blog en formato Word ocupan muchas veces no más que una o dos páginas, llegando muy raramente a las cuatro o cinco. ${ }^{29}$

En todo caso la brevedad es una virtud muy apreciada por estos pagos, no solamente respecto a los tiempos de lectura, sino a una necesidad de síntesis, de expresar sucinta

${ }^{29}$ Hay excepciones que admiten una extensión más larga, sobre todo en los blogs de Letras Libres que confirman la diferencia entre blogs personales e institucionales.

Revista Iberoamericana, Vol. LXXVIII, Núm. 240, Julio-Septiembre 2012, 657-679
ISSN 0034-9631 (Impreso) 
y claramente las ideas: una característica que se remonta a la brevitas de Cicerón y Quintiliano, de los antiguos manuales de retórica a las normas de disposición del texto que presentaba el ornatus, y que se utilizan por ejemplo en el género del resumen o en cualquier buen manual de escritura periodística. ${ }^{30}$ Lo nuevo es que estas normas se generalicen, y que le acompañen a problemas de arquitectura de las páginas web, ya que el objetivo es llegar a la lectura integral del texto en la pantalla. No se trata, sin embargo, de una brevedad obtenida gracias a la tachadura de elementos, sino más bien de una concisión obtenida por medio de una escritura esencial, de un razonamiento instantáneo, de la capacidad de unir elementos diferentes en pocas líneas.

En realidad parece claro que muchas de las cuestiones que se evidencian a este propósito ya se han ido planteando en la literatura crítica sobre el microcuento o la microficción. Si se observan de cerca las diversas teorías sobre estas formas de narraciones breves, expuestas por ejemplo en el ensayo de David Lagmanovich (2006), se descubre que muchas de aquellas consideraciones funcionan también en el campo del análisis de los blogs, y a través de ellas se puede desdibujar una primera aproximación a una teoría del microensayo que se podría referir a los blogs. Lagmanovich en efecto pone de relieve que la concisión, y no la brevedad, es la característica más relevante de la microficción y que justamente los textos más breves no nacen de un "proceso de achicamiento o abreviatura”, sino de otro proceso exactamente contrario:

La concisión característica de los microrrelatos no procede de tachar palabras, sino de agregarlas sobre la hoja de papel o la pantalla del ordenador. ¿Agregar? Sí: agregar, como en todo texto literario. La escritura consiste en crear una cadena de símbolos, sobre la blancura del papel o la neutralidad de la pantalla, que puedan suscitar en un lector otra imagen, la de cierto significado o significados que muy probablemente estarán más allá de las palabras, en la hondura de la comprensión por parte de ese ser humano. Para ello se comienza por formular una palabra, a la cual siguen otras, hasta llegar al final del texto. El truco del escritor de microrrelatos consiste en agregar todas las palabras necesarias y ninguna de las innecesarias. (41, énfasis mío)

Estas afirmaciones pueden aplicarse a la escritura ensayística del blog y encontrarían quizás sus antecedentes en el aforismo, en algunos géneros periodísticos y en tipos de microrrelatos como las fábulas: no es una casualidad que uno de los autores de los blogs de Letras Libres, José de la Colina, es también un apreciado autor de microrrelatos, y algunos de ellos se pueden encontrar en su Correo Fantasma. La búsqueda de posibles antepasados no puede esconder la novedad de la escritura de la que estamos hablando: el

${ }^{30}$ Véase, como introducción al tema, el ensayo de Fiormonte (2004) y, sobre la web usability se puede consultar el sitio de la Web Accesibility Inititative <http://www.w3.org/WAI> y los ensayos de Nielsen (1999) y de Norman (1998).

\footnotetext{
Revista Iberoamericana, Vol. LXXVIII, Núm. 240, Julio-Septiembre 2012, 657-679 ISSN 0034-9631 (Impreso) 
blog resulta, como hemos visto, del cruce de diferentes formas de escritura ya existentes, pero de por sí se presenta como un producto nuevo. ${ }^{31}$

En efecto, si los ensayos que hemos encontrado pueden inscribirse en la estrategia de una retórica de la brevedad aplicable a géneros muy variados, la forma del blog, con su voluntad dialógica, revela diferencias importantes; en muchos casos la brevedad llevaba consigo la necesidad de convencer, de afirmar una verdad incontrovertible, y ésta era la razón que aconsejaba el uso de la brevedad a los oradores en los antiguos manuales: había que convencer al juez, eliminando cualquier duda o interpretaciones alternativas. En cambio el ensayo quiere ir en el sentido exactamente contrario: sembrar dudas, proponer nuevos caminos, aunque sea con instrumentos polémicos, y los blogs que hemos analizado van en esta dirección. Se nota así en la escritura del blog el predominio de esta actitud dialógica que lo inclina hacia una escritura mucho menos organizada y estable de lo que se podría esperar en un género breve, una escritura que deja en el camino huecos, espacios vacíos que el lector tendrá que ocupar. ${ }^{32}$

La elección de la brevedad implica, en cierta medida, una tendencia hacia otro aspecto del blog que hay que señalar. Los bloggers, o por lo menos los mejores entre ellos, se orientan hacia una levedad del pensar que podría ser una calidad intrínseca a la Red por su naturaleza virtual e inmaterial, pero quien frecuenta este mundo bien sabe que existe también una Red muy pesada: páginas que resultan ilegibles, sitios gráficamente irreprochables pero de contenido insoportable. Por otro lado, la Red podría transformarse también en el reino de lo efímero, de una mermelada de impresiones sin consistencia, de vida muy breve. Los blogs de Faverón Patriau, de Letras Libres y de Rodríguez Mondoñedo presentan ejemplos difundidos de esta levedad del pensamiento, capaz de mirar el mundo desde perspectivas nuevas, como sugería Calvino en sus propuestas para un milenio que ya es el nuestro:

En los momentos en que el reino de lo humano me parece condenado a la pesadez, pienso que debería volar como Perseo a otro espacio. No hablo de fugas al sueño o a lo irracional. Quiero decir que he de cambiar mi enfoque, he de mirar el mundo con otra óptica, otra lógica, otros métodos de conocimiento y de verificación. Las imágenes

${ }^{31}$ Otro aspecto de la brevedad que se puede señalar es su relación con una "poética del fragmento" que se está desarrollando en estos últimos años. Un blog que se podría acercar más a este tipo de poética es, por ejemplo, el de Linkillo, del crítico argentino David Link. Sin embargo en este caso me parece que el tipo de escritura se va alejando del ensayo, por lo menos en la mayoría de las entradas, para acercarse más a los apuntes, a las notas de cuaderno, quizás volviendo al origen mismo del blog. La fragmentación no es aquí sinónimo de brevedad.

32 Cuando eso no pasa, como en algunas de las entradas políticas de Guillermo Sheridan o en las crónicas de Puente aéreo, la escritura cambia: se impone el uso del presente indicativo y muchas veces los comentarios que se van añadiendo construyen sólo un mosaico de opiniones en contraste, más que una búsqueda en común.

Revista Iberoamericana, Vol. LXXVIII, Núm. 240, Julio-Septiembre 2012, 657-679
ISSN 0034-9631 (Impreso) 2154-4794 (Electrónico) 
de levedad que busco no deben disolverse como sueños por la realidad del presente y del futuro. (23)

Llegando al final de estas reflexiones, podemos apuntar algunas cuestiones frente al futuro, como una respuesta abierta a nuestra pregunta inicial. Un primer asunto se refiere a la comunidad de lectores que se forma alrededor de los blogs: más allá de la calidad de las intervenciones, se nota en los últimos tiempos una disminución de los comentarios, ya que muchos lectores van migrando hacia otras formas de escritura personal en el web (social networks de varios tipos, Facebook, etc.): ${ }^{33}$ un cambio de actitud de los internautas que puede actuar como una selección natural en el mundo de los blogs, de manera que la posibilidad de sobrevivir de los mismos se irá midiendo por sus contenidos y por la riqueza de los enlaces, por la capacidad de construir redes de relaciones virtuales, de abrir nuevas vías de difusión para el mundo cultural latinoamericano. ${ }^{34}$

En este sentido el trabajo que ya están haciendo los bloggers parece de gran importancia: las fronteras entre países diferentes, que el libro y las revistas publicadas sobre papel muchas veces no conseguían rebasar, se derrumban frente a las posibilidades de comunicación en la Red, y los debates se abren fuera de los límites de las comunidades nacionales. El alcance de la Red permite además reunir voces dispersas en América Latina, Estados Unidos y Europa, que por fin llegan a compartir un espacio común, donde se pueden intercambiar ideas, hasta opiniones opuestas (no hay que olvidar la forma polémica de algunas de las entradas analizadas), que no quedan atrapadas en el huerto cerrado de cada autor. Aquí la ruptura del sentido tradicional del concepto de espacio puede servir también como reapropiación de un lugar propio: el hecho que se puedan proponer contenidos heterogéneos desde los ángulos más dispersos del planeta permite vencer posibles usos neocolonialistas de la Red. ${ }^{35}$

33 En diciembre de 2008 en la Red ya se había hablado de la posible "muerte del blog" frente a otros medios de comunicación: se puede ver, por ejemplo, la entrada de Etiqueta Negra que contiene enlaces a otros artículos: <http://etiquetanegra.com.pe/?p=280748>. Me parece que este peligro ya no existe, vista la buena salud de los blogs analizados.

${ }^{34}$ Recientemente se puede notar otro fenómeno de tipo editorial: la publicación en libros de papel de una "selección" de las "mejores" entradas de algunos bloggers más conocidos. Me parece que todo esto no es otra cosa que una explotación comercial de material ya existente y que al pasar de la red al papel la escritura de la Red pierde justamente por lo menos tres de las características más novedosas que se han subrayado en este artículo: la interactividad, la pluralidad y la relación con la imagen.

35 Taylor y Pitman (2008) se refieren en su artículo sobre la posibilidad de un uso neocolonialista de la Red y de las medidas necesarias para evitarlo. Se podría añadir que las grandes posibilidades de conocimiento de la Red no siempre corresponden a una efectiva apertura de intercambio de los instrumentos básicos de conocimiento: cualquier usuario de la Red se puede enterar de la salida de libros de su interés en cualquier lugar del mundo pero, ¿puede acaso llegar a consultarlos con la misma facilidad? Por otro lado, el mismo Calvino nos recuerda otra vez cómo la calidad de las ideas va a ser el punto discriminante: "Como en cada una de estas conferencias me he propuesto recomendar al próximo

\footnotetext{
Revista Iberoamericana, Vol. LXXVIII, Núm. 240, Julio-Septiembre 2012, 657-679 ISSN 0034-9631 (Impreso) ISSN 2154-4794 (Electrónico)
} 
Otro tema relativo a los blogs que se ha ido asomando entre líneas durante la exploración de la escritura en la Red es la posición del yo que la misma estrategia de construcción de un blog pone en primer plano: en los blogs personales la presentación del autor se encuentra a la derecha de los textos, inmediatamente visible, y en los institucionales es fácilmente accesible con un enlace. Una posición que implica que la escritura del blog esté dominada por la presencia muy fuerte de un yo puesto al descubierto, ofrecido a la mirada del lector con todas sus idiosincrasias, sus defectos, sus pasiones y que a veces desborda de los límites de la escritura. Una faceta que remite evidentemente a su origen como diario de a bordo personal, una especie de biografía digital. Cabe preguntarse en qué medida este matiz puede compaginarse con las características del ensayo recordadas hasta ahora: parece obvio que el autor, aun con esta presencia tan evidente, tiene que dejar en claro su posición dentro de una comunidad más amplia, proponer sus entradas como contribución a lo que ya llamamos la Gran Conversación, ponerse en juego a través de una articulación inteligente de preguntas y respuestas. Esta posición recuerda de alguna manera lo que Cortázar define como "el sentimiento de no estar del todo":

Escribo por falencia, por descolocación; y como escribo desde un intersticio, estoy siempre invitando a que otros busquen los suyos y miren por ellos al jardín donde los árboles tienen frutos que son, por supuesto, piedras preciosas. (32)

La Red podría entonces revelarse como este intersticio, como el lugar donde invitar los otros a buscar lo suyo: el ensayista del blog tendrá quizás que buscar, él también, un equilibrio entre su presencia real, con su función creadora y reguladora, y su desaparición, su de-corporeización, la pérdida del peso del autor y la dinámica del saber que se va construyendo en el espacio virtual..$^{36}$ Esta aparición del “yo" en el campo del blog sigue, por otro lado, la evolución del "yo" de la crítica en los dos últimos siglos, como se ha delineado por ejemplo en la labor de Rosalba Campra, ya que aquí también:

El afloramiento cada vez más marcado del yo en la escritura crítica actual me parece sobre todo como una de las consecuencias del giro relativista de la epistemología contemporánea, que tanto ha subrayado la importancia de la posición del observador en la determinación de la materia de estudio. (104)

milenio un valor que me es caro, hoy el valor que quiero recomendar es justamente éste: en una época en que triunfan otros media, velocísimos y de amplísimo alcance, y en que corremos el riesgo de achatar toda comunicación convirtiéndola en una costra uniforme y homogénea, la función de la literatura es la de establecer una comunicación entre lo que es diferente en cuanto es diferente, sin atenuar la diferencia sino exaltándola, según la vocación propia del lenguaje escrito” (57-58).

${ }^{36}$ Habla de este tema Claire Taylor (2008, 244ss) referiéndose a los cuerpos virtuales del ciberespacio.

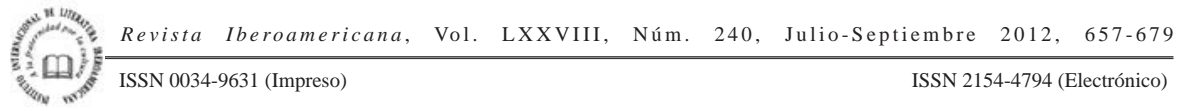


Así pues, la escritura crítica me parece marcada ya sea por la idea de autorrepresentación como impertinente y, consecuentemente por una atenuación discreta del yo, ya sea por la reivindicación del peso del yo en las elecciones críticas - en el peor de los casos, por la concesión a las tentaciones exhibicionistas. (105)

El ensayista del blog podría llegar a ser así, como nos recuerda Evodio Escalante:

[...] un campeón del pensamiento aproximativo. No le interesa la verdad sino esa peculiar aproximación a la verdad que se llama lo verosímil. En esto el ensayista es un novelista de los conceptos. Así como interesa al narrador mantener la verosimilitud de su relato, así el primer deber del ensayista es el de darle visos de credibilidad a sus tanteos en el campo del pensamiento. Como la necesidad no es lo suyo -el ensayo se convertiría ipso facto en tratado, monografía o disertación-, el ensayista ha de manejarse en el campo de lo probable. (302)

El campo de lo probable y la red virtual plantean, mirando hacia otra dirección, un problema temporal: ¿el producto cultural que aparece en los blogs, qué duración puede tener? O, en otro sentido, ¿tiene que durar en el tiempo? ¿ंo puede ser solamente un producto efímero, pasajero? Sabemos muy bien cómo ya la Red resulta ser también un inmenso cementerio de productos virtuales (lo atestigua el hecho de que en las web-grafías hay que poner la fecha del último acceso efectuado), y nos preguntamos si encontraremos los blogs que hemos analizado dentro de diez años. Esto es una pregunta que por el momento no encuentra una respuesta clara, quedando abierta para un debate ulterior. ${ }^{37}$

Una de las propuestas de Calvino se quedó desafortunadamente en el tintero, y quizás sea la que pueda ayudarnos a concluir esta reflexión: la última tenía que ser la consistencia, y esto nos recuerda que el espacio virtual no puede prescindir del espacio real, que las dos realidades tienen que entrelazarse como los libros (los reales, de papel verdadero) con sus lectores, que los actores tienen que encontrarse, como nos recuerda la cubana Yoani Sánchez en uno de los blogs más visitados del continente, Generación $Y$. En ocasión del premio del jurado al mejor Weblog y del galardón de Reporteros sin Fronteras en el certamen The Bobs, Yoani Sánchez escribe:

Pues sí, hay mucho que me falta todavía. No son precisamente premios, sino derechos largamente postergados, como el de poder ser leída dentro de mi propio país. Aún me

${ }^{37}$ Gustavo Faverón me decía, en un intercambio electrónico de opiniones, que el resultado más significativo de su blog ha sido la publicación de la antología de cuentos Todas las sangres, sobre la violencia política en el Perú, nacida justamente a raíz de una discusión del blog: un libro de papel que ha permitido reunir cuentos dispersos y ponerlos a la atención de un público amplio. No creo que vaya hacia la misma dirección la moda reciente de publicar en formato de libro "lo mejor" de algunos blogs existentes en la Red.

\footnotetext{
Revista Iberoamericana, Vol. LXXVIII, Núm. 240, Julio-Septiembre 2012, 657-679 ISSN 0034-9631 (Impreso) ISSN 2154-4794 (Electrónico)
} 
debo a mí misma el decir todo esto en el mundo real y no en la virtualidad de una bitácora. Pasar esta plaza cívica que es hoy Generación Y a una existencia concreta donde también abundan los trolls y el castigo es más fuerte que un simple hackeo. Necesito algo más que kilobytes, estoy precisada de realidades.

Carecemos aún -y ese es el más ansiado galardón- del derecho a dialogar, disentir y teñirnos del color político que queramos al interior de la Isla. No dejemos que este sea sólo un fenómeno reducido a la blogósfera, hay que ir en busca del premio gordo: la libre opinión. ${ }^{38}$

\section{BiBLIOGRAFÍA}

Berners-Lee, T. Weaving the Web, The Past, Present and Future of the World Wide Web by its Inventor. Londres: Texere, 2000. Traducción italiana: L'architettura del nuovo Web. Milano: Feltrinelli, 2001.

Bruguera, Enric. Los blogs. Barcelona: Editorial UOC, 2007.

Calvino, Italo. Seis propuestas para el próximo milenio. Barcelona: Siruela, 1998. Trad. de Lezioni americane. Milano: Garzanti, 1988.

Campra, Rosalba. “El ‘yo’ de la crítica entre autobiografía y ficción”. Río de la Plata 20-21 (1998): 97-106.

Cortázar, Julio. "Del sentimiento de no estar del todo". La vuelta al día en ochenta mundos. Madrid: Siglo XXI de España, 1967. 32-42.

Dellarocas, C. The Digitization of Word-of-Mouth: Promise and Challenges of Online FeedbackMechanisms. Octubre 2003. <http://digital.mit.edu/research/papers/173_ Dellarocas_Word_of_Mouth.pdf $>$.10 sept. 2011.

Di Fraia, Guido. "Il fenomeno blog”. Blog-grafie. Identità narrative in rete. Guido Di Fraia, ed. Milano: Guerini, 2007. 9-47.

Earle, Peter G. y Robert G. Mead, Jr. Historia del ensayo hispanoamericano. México: De Andrea, 1973.

Escalante, Evodio. "La metáfora como aproximación a la verdad. Ensayo acerca del ensayo”. Las metáforas de la crítica. México: Joaquín Mortiz, 1998. 285-310.

Fiormonte, Domenico. "La testualità digitale oggi: dalle scritture on-line alla Web usability”. Scrittura e nuovi media. Franca Orletti, ed. Roma: Carocci, 2004. 43-67.

García Fernando y Andrés Hax. "El ensayo en tipos de blog”. N. 11 enero 2004. <http:// www.revistaenie.clarin.com/notas/2008/01/11/01582985.html> 10 sept. 2011.

Granieri, Giuseppe. Blog Generation. Roma-Bari: Laterza, 2005.

\footnotetext{
${ }^{38}$ El blog de Generación $Y$ es uno de los blogs más seguidos de todo el continente y uno de los más interesantes, pero no lo hemos incluido en nuestro análisis porque creemos que sus contenidos se acoplan mejor a una visión del blog como la crónica a la que aludimos antes. La cita viene de la página: $<$ http//www.desdecuba.com/generaciony/?p=565>.

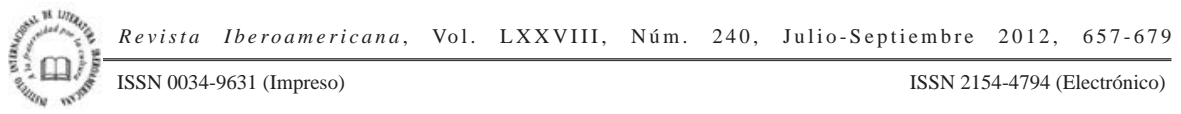


Hevern, V.W. y Pugliese A.C. "Identità virtuali che si intrecciano con la storia: i weblog e le pratiche discorsive del sé”. Identità dialogiche nell'era digitale. Logorio M.B. y Hermans, H., Gardolo, Erickson, 2005. 65-76.

Lagmanovich, David. El microrrelato. Teoría e historia. Palencia: Menoscuarto, 2006. Nielsen, J. Designing Web Usability. Indiana: New Riders, 1999.

Norman, D. The Invisible Computer. Cambridge: MIT, 1998.

Orletti, Franca. "Conversazioni in rete". Scrittura e nuovi media. Franca Orletti, ed. Roma: Carocci, 2004. 113-31.

Oviedo, José Miguel. Breve historia del ensayo hispanoamericano. Madrid:Alianza, 1990.

Paz Soldán, Edmundo. “A Cyberliterary Afterword: Of Blogs and Other Matters”. Latin American Cyberculture and Cyberliterature. C. Taylor y T. Pitman, eds. Liverpool: Liverpool UP, 2008. 257-61.

Rix, Rob. "Julio Cortázar's Rayuela and the Challenges of Cyberliterature”. Latin American Cyberculture and Cyberliterature. C. Taylor y T. Pitman, eds. Liverpool: Liverpool UP, 2008. 194-206.

Stabb, Martin S. The Dissenting Voice. The New Essay of Spanish America, 1960-1985. Austin: U of Texas P, 1994. In Quest of Identity: Patterns in the Spanish American Essay of Ideas. Chapel Hill: U of North Carolina P, 1967.

Taylor, Claire y Thea Pitman. Introducción. Latin American Cyberculture and Cyberliterature. C. Taylor y T. Pitman, eds. Liverpool: Liverpool UP, 2008. 1-30.

Taylor, Claire. "Virtual Bodies in Cyberspace: Guzik Glantz's Weblog”. Latin American Cyberculture and Cyberliterature. C. Taylor y T. Pitman, eds. Liverpool: Liverpool UP, 2008. 244-56.

\section{WEB-GRAFÍA}

Sitos citados en el texto:

(última consulta 10 septiembre 2011)

Artifara: http://artifara.com/

Crítica.cl: http://www.critica.cl/

Etiqueta Negra: http://etiquetanegra.com.pe/

Generación Y (Yoani Sánchez): http://www.desdecuba.com/generaciony/

Proyecto Letral: http://www.proyectoletral.es/

Letralia: http://www.letralia.com/

Letras Libres: http://www.letraslibres.com/blog/blogs/

Linkillo (Daniel Link): http://www.linkillo.blogspot.com/

La Peña Lingüística (Miguel Rodríguez Mandoneño): http://lapenalinguistica.blogspot. $\mathrm{com} /$

Puente Aéreo (Gustavo Faverón Patriau): http://puenteareo1.blogspot.com/

Revista Iberoamericana, Vol. LXXVIII, Núm. 240, Julio-Septiembre 2012, 657-679
ISSN 2154-4794 (Electrónico) 
